\title{
Preparation of Homogeneous Nanostructures in 5 Minutes for Cancer Cells Capture
}

\author{
Lixue Wang, ${ }^{1,2}$ Chuandong Zhu, ${ }^{1}$ Qin Zheng, ${ }^{1}$ and Xia $\mathrm{He}^{3}$ \\ ${ }^{1}$ Department of Oncology, The Second Affiliated Hospital of Southeast University, Nanjing, Jiangsu 210003, China \\ ${ }^{2}$ The Fourth Clinical Medical College of Nanjing Medical University, Nanjing, Jiangsu 210009, China \\ ${ }^{3}$ Department of Radiation Oncology, The Affiliated Jiangsu Cancer Hospital of Nanjing Medical University, Nanjing, \\ Jiangsu 210009, China
}

Correspondence should be addressed to Qin Zheng; txzzzq@sina.com and Xia He; zghexia@sina.com

Received 30 December 2014; Revised 28 March 2015; Accepted 31 March 2015

Academic Editor: Yaling Liu

Copyright (C) 2015 Lixue Wang et al. This is an open access article distributed under the Creative Commons Attribution License, which permits unrestricted use, distribution, and reproduction in any medium, provided the original work is properly cited.

Grafting aptamers on nanostructured substrates has shown ultrasensitivity in isolation of circulating tumor cells (CTCs). Here, we report that over $80 \mathrm{~cm}^{2}$ of homogenous nanostructured surface on glass substrates can be prepared in 5 min after one-step dry etching. The surface area was doubled; the average diameter of nanostructures is approximately $374 \mathrm{~nm}$, which is more close to the nanostructures of natural extracellular matrix. Antiepithelial cell adhesion molecule aptamers grafted nanostructured glass substrates captured over $76 \%$ of PC 3 cells compared to $30 \%$ of planar substrates. Bispecific aptamers cofunctionalized nanostructured substrates, however, fail to capture cancer cells probably due to the formation of heterodimers. This limitation reveals that multispecific aptamers, when applied to cell isolation, must be analyzed to exclude any potential formation of heterodimers due to complementary sequence matching.

\section{Introduction}

Circulating tumor cells (CTCs) as emerging tumor biomarkers can provide valuable information for clinical diagnosis, prognosis, and treatment [1-5]. Over the last decade, numerous methods for detection and isolation of CTCs have been developed [6]. Recently, nanostructured substrates have emerged as very promising tools. They provide more surface area for ligands immobilization and lower the rolling velocity of cells in microchannels $[7,8]$. Cancer cells also can dynamically arrange focal adhesion points [9]. However, there are two major challenges. First, due to the limitations of existing nanofabrication techniques, large-scale fabrication of homogeneous nanostructured substrates is nontrivial [10, 11]. These nanostructured substrates in small pieces ( $\left(\mathrm{few} \mathrm{cm}^{2}\right.$ ) only process a limited amount of blood at a time $(\leq 1 \mathrm{~mL})$ [1]. Clinically relevant CTCs detection approaches should be able to process at least $7.5 \mathrm{~mL}$ of blood [12]. Thus, preparation of homogeneous nanostructures in large area is compulsory. Heterogeneity of CTCs poses the other challenge. Currently biological isolation approaches heavily rely on antiepithelial cell adhesion molecule (EpCAM). However, CTCs may have little or no expression of EpCAM on the cell membrane [13], causing biased isolation of CTCs [14].

To prepare homogeneous nanostructures in larger area, we develop a new recipe using $\mathrm{C}_{3} \mathrm{~F}_{8}$ and $\mathrm{C}_{4} \mathrm{~F}_{8}$ as etchant gas and successfully obtain approximately $80 \mathrm{~cm}^{2}$ projected area of homogeneous nanostructures after one-step dry etching in $5 \mathrm{~min}$. Such area theoretically can process $8 \mathrm{~mL}$ whole blood samples for detection of CTCs [15]. On the other hand, to alleviate the challenge raised by heterogeneity of CTCs, we immobilize bispecific aptamers on nanostructured glass surface for cancer cells isolation. Aptamers are singlestranded oligomers that can specifically recognize and bind to target protein [16]. They are chemically stable at a wide range of $\mathrm{pH}$, temperature, and ionic conditions [17]. Moreover, aptamers can be prepared in large quantity without batch-tobatch variation [18]. Bispecific aptamers have been used for targeted drug delivery [19]. However, it is unknown whether bispecific aptamers are able to increase isolation efficiency of 
TABLE 1: Sequences of respective aptamers and control DNA.

\begin{tabular}{ll}
\hline Name & Sequence $\left(5^{\prime} \rightarrow 3^{\prime}\right)$ \\
\hline AEA $[18]$ & AAA AAA AAA AAA CAC TAC AGA GGT TGC GTC TGT CCC ACG TTG TCA TGG GGG GTT GGC CTG \\
\hline APA [16] & AAA AAA AAA AAA GCG TTT TCG CTT TTG CGT TTT GGG TCA TCT GCT TAC GAT AGC AAT GCT \\
Control DNA & AAA AAA AAA AAA CTG TCT TCG CGC CTA GCG CGA CCA TGT TAC AGA GCA GTG ATT TAG AGG \\
\hline
\end{tabular}

cancer cells yet. To test the isolation efficiency, anti-EpCAM aptamers (AEA) or antiprostate specific membrane antigen (PSMA) aptamers (APA) are used.

Our results show that nanostructures with diameters ranging from 127 to $413 \mathrm{~nm}$ are successfully prepared, and nanostructured substrates can significantly increase cell capture efficacy. However, bispecific aptamers of AEA/APA mixture fail to capture PC3 cells due to the potential formation of heterodimers.

\section{Materials and Methods}

All chemicals were obtained from Sigma-Aldrich unless otherwise noted.

2.1. Glass Slides Etching and Characterization. The glass slides (Borofloat 33, Schott) were cleaned in piranha solution for $10 \mathrm{~min}$ at $90^{\circ} \mathrm{C}$., followed by rinsing with DI water and drying in nitrogen flow. To create nanostructured surfaces, plain glass surface was subjected to RIE (ULVAC, NLD570 oxide etcher) for 3 to $15 \mathrm{~min}$. The RIE condition was selected as $\mathrm{C}_{3} \mathrm{~F}_{8}$ (30 sccm), $\mathrm{C}_{4} \mathrm{~F}_{8}(10 \mathrm{sccm}), \operatorname{Ar}(50 \mathrm{sccm}), \mathrm{O}_{2}(10 \mathrm{sccm})$, antenna power $(2000 \mathrm{~W})$, bias power (50-200 W), and chamber pressure ( 5 mTorr). After the RIE process, the glass surface was cleaned using piranha solution and DI water. Surface topography was evaluated quantitatively using a JPK atomic force microscope (AFM). Images of $10 \times 10 \mu \mathrm{m}$ area were captured in tapping model.

2.2. Cell Culture. PC3 cells $\left(\mathrm{EpCAM}^{+} / \mathrm{PSMA}^{-}\right)$were cultured in DMEM supplemented with 10\% FBS, penicillin:streptomycin $100 \mathrm{U} / \mathrm{mL}$ and plated in T-25 tissue culture flasks (Corning, US). Flasks were placed into an incubator maintaining $5 \% \mathrm{CO}_{2}$ at $37^{\circ} \mathrm{C}$ and $10 \%$ humidity.

2.3. Aptamers Binding to Cancer Cells. The respective sequences of AEA and APA (Sangon, Shanghai) were shown in Table 1. To confirm the binding of aptamer to cancer cells, Cy3 fluorescent groups labelled AEA, APA, and control DNA were incubated with PC3 cells. The aptamers were denatured by heating samples to $70^{\circ} \mathrm{C}$ for 5 minutes and then slowly cooling to RT. Cells in duplicate were seeded into 6-well cell culture plate and cultured for 48 hours. The aptamers and control DNA were incubated with cells at $37^{\circ} \mathrm{C}$ for 30 minutes under $5 \% \mathrm{CO}_{2}$. After incubation, the cells were washed with 1x PBS three times, fixed with $4 \%$ paraformaldehyde for $30 \mathrm{~min}$, and then stored in 1x PBS for optical and fluorescence imaging. The fluorescence images were taken followed by analysis of fluorescence intensity with ImageJ.
2.4. Immobilize Aptamers onto Nanostructured Glass Surface. All glass samples were immersed in 5\% 3-aminopropyltriethoxysilane (APTES) in ethanol for $2 \mathrm{~h}$ at RT. The silanized substrates were then sequentially rinsed with DI water and cured at $120^{\circ} \mathrm{C}$ for $1 \mathrm{~h}$. The substrates were then immersed in a dimethylformamide (DMF) solution containing $10 \%$ pyridine and $1 \mathrm{mM}$ phenyldiisothiocyanate (PDITC) for 2 hours. Each substrate was then washed sequentially with DMF and 1,2-dichloroethane and dried under a stream of nitrogen. The amine group modified aptamers were prepared at $30 \mu \mathrm{M}$ in DI water (ratio of AEA/APA: $1: 3,1: 1$, and $3: 1$ ). A volume of $25 \mu \mathrm{L}$ of aptamer solution was placed on each substrate and allowed to incubate in a humidity chamber at $37^{\circ} \mathrm{C}$ overnight. Each substrate was then sequentially washed with methanol and DI water. The functionalized surface was then deactivated by capping unreacted PDITC moieties by immersion in $50 \mathrm{mM}$ 6-amino-1-hexanol in DMF for 5 hours. Each substrate was then sequentially rinsed with DMF, methanol, and DI water.

2.5. Cell Capture Assay and Image Analysis. Four devices functionalized with AEA, APA, AEA/APA, and control DNA, respectively, were prepared for each type of cell. $1 \times 10^{5}$ cells $/ \mathrm{mL} 500 \mu \mathrm{L}$ of cell suspension was seeded onto $1 \times 1 \mathrm{~cm}$ device surface and incubated at $37^{\circ} \mathrm{C}$ for $30 \mathrm{~min}$, and then $1 \mathrm{x}$ PBS was used to wash off the nonspecifically bound cells. Captured cells were fixed with $4 \%$ paraformaldehyde for $1 \mathrm{~h}$ at RT and then treated with permeabilizing block buffer (1x PBS with $0.5 \%$ sodium azide supplemented with $0.05 \%$ Triton X100 and $10 \%$ BSA). Cells were then washed with perm wash $1 \mathrm{x}$ PBS supplemented with $0.5 \%$ sodium azide followed by $0.1 \mu \mathrm{g} / \mathrm{mL}$ DAPI staining. The whole glass slide was analyzed using Cytell (GE, US) high-content imaging system using 10x objectives. The number of captured cells was counted through DAPI stained nuclei of cells. Cell capture efficiency was then defined as the ratio of the number of captured cells to the total number of cells.

2.6. Electrophoresis Analysis of Heterodimers. $8 \mu \mathrm{L}$ of AEA and $8 \mu \mathrm{L}$ of APA at $50 \mathrm{pM}$ in $1 \mathrm{x}$ PBS were well mixed and denatured at $95^{\circ} \mathrm{C}$ for $5 \mathrm{~min}$ and then slowly cooled to RT. $8 \mu \mathrm{L}$ of AEA or APA at $50 \mathrm{pM}$ in $1 \mathrm{x}$ PBS was treated by the same procedure. Samples were analyzed by $4 \%$ agarose gel electrophoresis at $80 \mathrm{~V}$ at $4^{\circ} \mathrm{C}$.

\section{Results and Discussion}

3.1. Characterization of Nanostructures. AFM images of samples and quantified results are shown in Figure 1 and Table 2. 


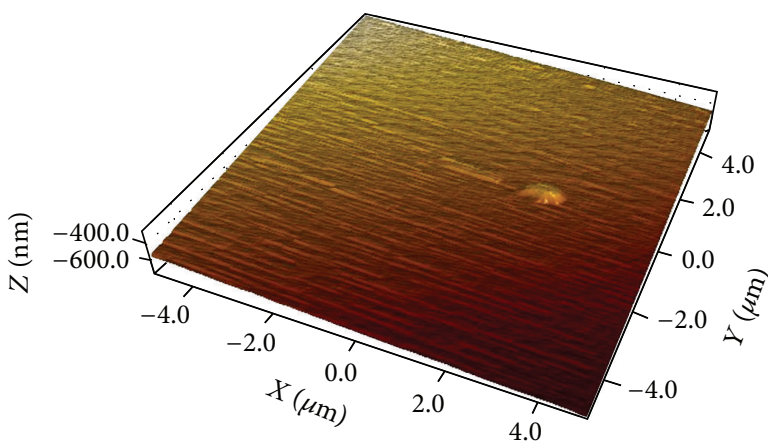

(a)

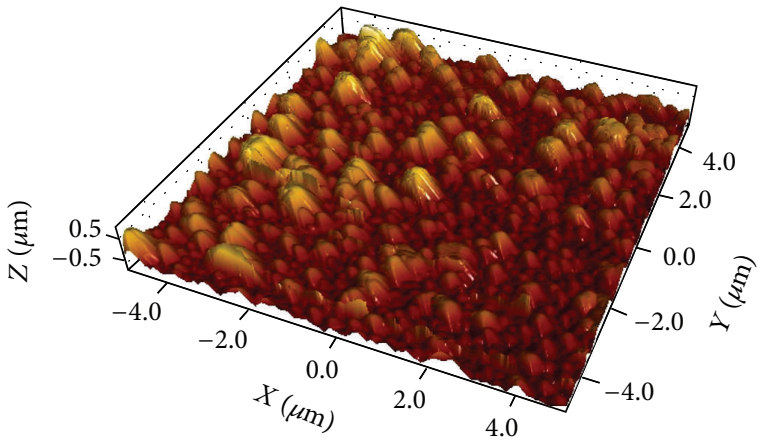

(c)

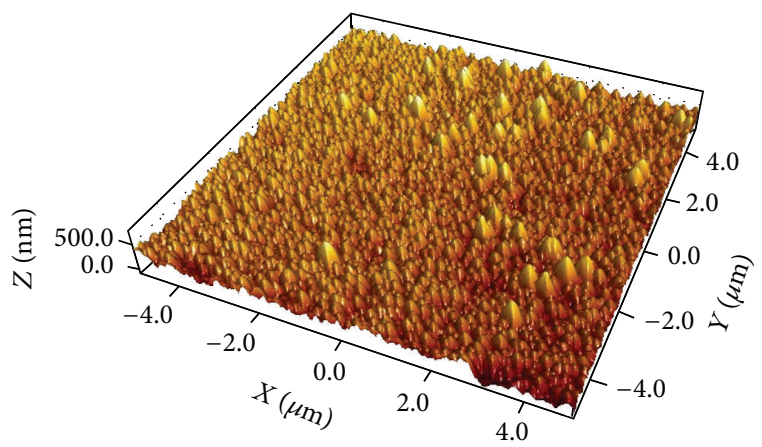

(b)

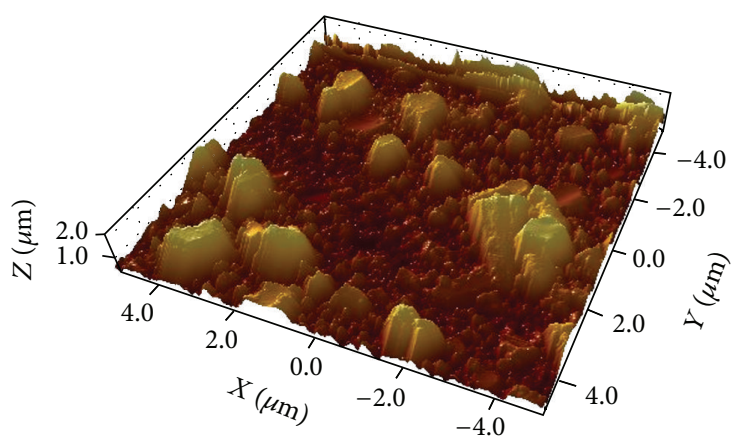

(d)

Figure 1: AFM images $\left(10 \times 10 \mu \mathrm{m}^{2}\right)$ of the surface roughness of etched glass. (a) shows glass surface before etching; (b) shows glass etched at $50 \mathrm{~W}$ for $5 \mathrm{~min}$; (c) shows glass etched at $100 \mathrm{~W}$ for $5 \mathrm{~min}$; (d) shows glass etched at $200 \mathrm{~W}$ for $5 \mathrm{~min}$.

TABLE 2: Characterization of glass substrates under different etching conditions.

\begin{tabular}{lccc}
\hline Etching condition & $\begin{array}{c}\text { Surface } \\
\text { area }\left(\mu \mathrm{m}^{2}\right)\end{array}$ & $\begin{array}{c}\text { Mean } \\
\text { diameter } \\
(\mathrm{nm})\end{array}$ & $R_{q}(\mathrm{~nm})$ \\
\hline Unetched & 102 & 2 & 6.5 \\
50 W 5 min & 191 & 126.8 & 77.9 \\
100 W 5 min & 212 & 374.3 & 203 \\
200 W 5 min & 363.5 & 412.9 & 382.4 \\
\hline
\end{tabular}

The increase of bias power can significantly increase the surface roughness. High bias power $(200 \mathrm{~W})$ is not ideal for preparation of homogeneous nanostructures and thus is excluded. Insular and abrupt microstructures are found probably due to fast etching rate (Figure $1(\mathrm{~d})$ ). We choose $100 \mathrm{~W}$ bias power and treatment for $5 \mathrm{~min}$ in following experiments. Previous research validated that cancer cell capture yield increased with nanoroughness [9]. Roughness of $203 \mathrm{~nm}$ obtained at $100 \mathrm{~W}$ is better. Moreover, the mean diameter of nanostructures obtained at $100 \mathrm{~W}$ for $5 \mathrm{~min}$ is $374.3 \mathrm{~nm}$ (Figure 1(c)). The size is more close to the nanostructures of natural extracellular matrix which fall in the range of 260 to $410 \mathrm{~nm}[1]$.

3.2. Aptamers Binding to Cancer Cells. To confirm AEA and APA can specifically recognize and bind to PC3 cells, Cy3

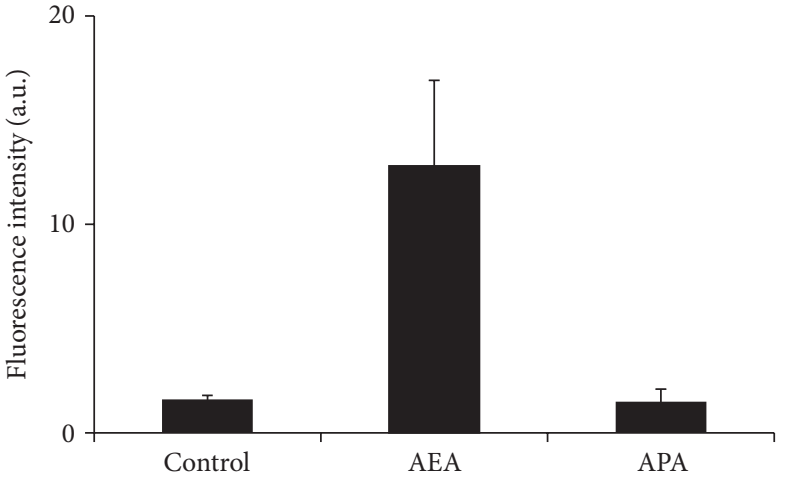

FIgURE 2: Average fluorescence intensity of AEA or APA binding to the LNCaP cells. Aptamers were allowed to interact and bind to cells at $37^{\circ} \mathrm{C}$ for $30 \mathrm{~min}$ in $5 \% \mathrm{CO}_{2}$. After binding, the cells were washed with $1 \mathrm{x}$ PBS three times.

labelled AEA, APA, and control DNA were directly incubated with cells. The fluorescence intensity of respective aptamers is shown in Figure 2. The fluorescence signals reveal that AEA can bind to PC3 cells that weakly express EpCAM. Previous study has confirmed that APA can specifically recognize and internalize into $\mathrm{PSMA}^{+}$cells with minimal uptake into PSMA $^{-}$PC3 cells [20]. We did not detect fluorescent signals from dye labelled APA because of null expression of PSMA on PC3 cell membrane. Nonspecific adsorption or binding of control DNA probes did not occur. 


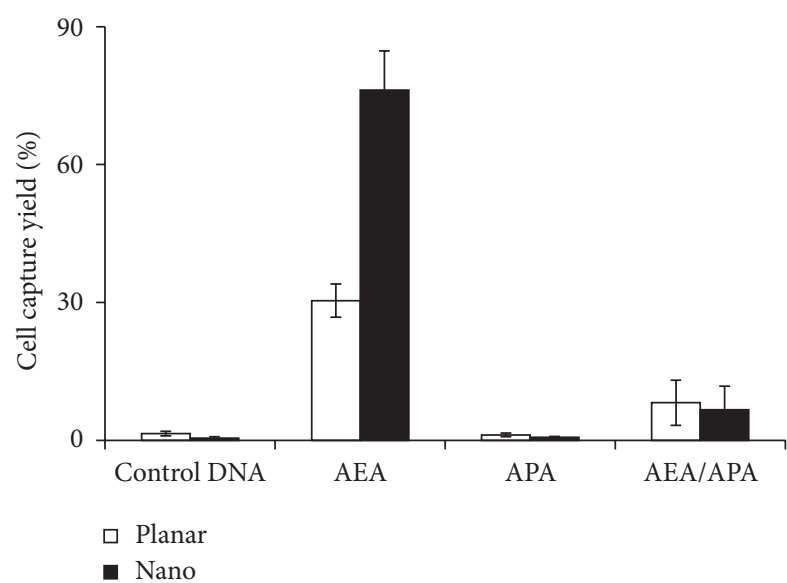

(a)

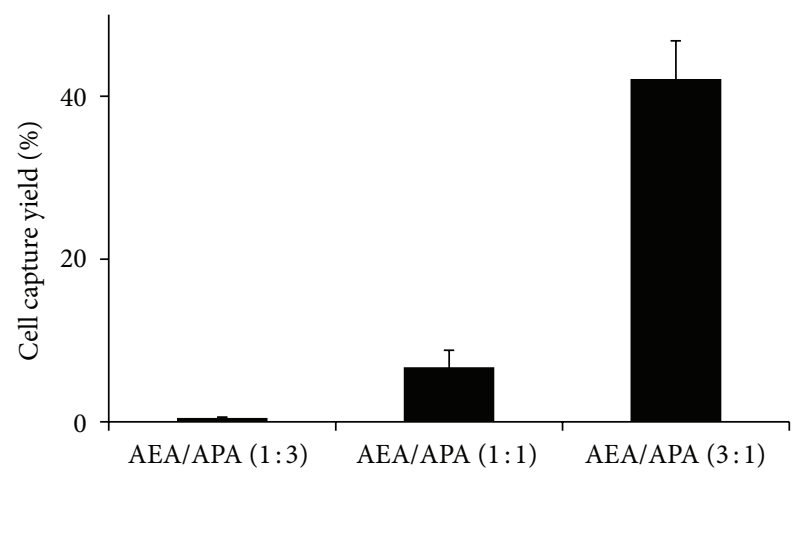

(b)

FIGURE 3: (a) shows average capture efficiency of PC3 cells on the AEA, APA, or AEA/APA functionalized planar and nanostructured surfaces; (b) shows differentiated capture efficiency of PC3 cells on the mixture of AEA and APA in ratio, respectively. $1 \times 10^{5}$ cells were seeded onto surfaces and incubated at $37^{\circ} \mathrm{C}$ for $30 \mathrm{~min}$ in $5 \% \mathrm{CO}_{2}$. After binding, the cells were washed with $1 \mathrm{x}$ PBS three times.

3.3. Cancer Cells Capture. We firstly compared the difference of capture yield of PC3 cells between planar and nanostructured substrates (Figure 3(a)). 30.4\% (SD: 3.6\%) and $76.2 \%$ (SD: $8.5 \%$ ) of PC3 cells were captured on planar and nanostructured glass substrates with AEA, respectively. The low capture efficiency of AEA functionalized planar surface might be raised by the inherent low-affinity interactions of aptamers [21]. The dissociation constant $\left(K_{d}\right)$ value of antiEpCAM aptamer is approximately $20 \mathrm{nM}$, and it is fluctuant depending on the types of target cells [22]. Moreover, low amount of EpCAM (51,667 EpCAM molecules per cell) may be unable to gain sufficient binding forces during washing procedure [23]. In contrast, AEA grafted nanostructured substrates increase capture yield through higher odds of binding and higher total binding forces between AEA and EpCAM. In control groups, 1.4\% (SD: 0.3\%) and 0.5\% (SD: $0.2 \%$ ) of cells were captured on control DNA grafted planar and nanostructured substrates, respectively. Because PC3 cells do not express PSMA on cell membrane, approximately $1.2 \%$ (SD: $0.4 \%$ ) and $0.7 \%$ (SD: $0.2 \%$ ) of cells were nonspecifically captured onto APA functionalized planar and nanostructured substrates, respectively. Together, AEA grafted nanostructured substrates show better cell capture yield compared to that of planar substrates.

Once we incubated PC3 cells on AEA/APA cofunctionalized planar and nanostructured substrates, cell capture yield decreased significantly. Only 8.2\% (SD: 4.9\%) and 6.7\% (SD: 5.1\%) PC3 cells were captured on planar and nanostructured substrates, respectively. It might be caused by heterodimer between AEA and APA. Further, we used mixed AEA/APA in different ratios $(1: 3,1: 1$, and $3: 1)$ to reveal the potential formation of heterodimers. PC3 cells capture yields were $0.5 \%, 6.7 \%$, and $42.1 \%$, respectively. If AEA and APA did not form any heterodimers, AEA/APA $(3: 1)$ theoretically could capture approximately $60 \%$ of PC 3 cells. However, in practical experiments, only $42 \%$ of cells were captured by AEA/APA in $3: 1$ ratio. The results indicated that a number of AEA were

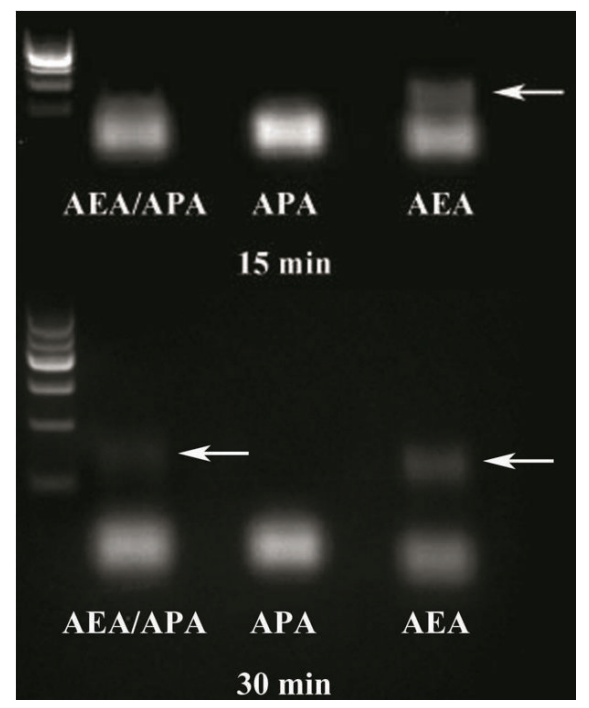

FIGURE 4: The potential heterodimer structure between AEA and APA. Electrophoresis of AEA, APA, and annealed AEA/APA at 15 and 30 min timepoints, respectively; samples were analyzed by $4 \%$ agarose gel electrophoresis at $80 \mathrm{~V}$ at $4^{\circ} \mathrm{C}$.

unable to form suitable tertiary structures and to participate into antigens reorganization and capture. Alternatively, AEA does form right hairpin structures, but the recognition parts may be blocked by APA. However, in our design, both AEA and APA have $12 \mathrm{nt}$ polyA spacer that can effectively prevent steric effect. Thus, the later speculation is invalid. The heterodimer analysis of AEA/APA and hairpin analysis of AEA or APA (IDT OligoAnalyzer 3.1) show the lowest Delta G value is $-8.09,-4.08$, and $-4.87 \mathrm{kcal} / \mathrm{mole}$, respectively. The values indicate all reactions are exergonic and spontaneous, and the heterodimer reaction between AEA and APA is more favourable. Figure 4 shows electrophoresis results of $16 \mu \mathrm{L}$ of AEA/APA, $8 \mu \mathrm{L}$ of APA, and $8 \mu \mathrm{L}$ of AEA, respectively, at 15 
and 30 min timepoint, respectively. If heterodimers do not exist, the mixture should show the exact same bands with that of AEA. Although an approximately 120-nt band appeared in both AEA and the mixture of AEA and APA, it is much weaker in the mixture. We speculate that, in the mixture, AEA and APA may form heterodimers after annealing. The continuous electrophoretic forces in $30 \mathrm{~min}$ gradually destroy these heterodimers [20, 21], and once AEA and APA are compulsorily separated the mixture begins to show the similar distribution of bands. We admit that we do not have direct evidences to confirm the heterodimers; nevertheless the electrophoresis results demonstrate that AEA and APA have mutual interactions that can impede their dissociation.

\section{Conclusion}

Homogeneous nanostructures in approximately $370 \mathrm{~nm}$ diameter can reliably and quickly be prepared on borosilicate glass slides using our recipe, and the aptamer functionalized nanostructured substrates can significantly improve cancer cell capture yield. However, bispecific aptamers cografted surface failed to capture cancer cells probably due to the formation of heterodimers. The potential shortcoming may impair the application of multispecific aptamers for detection and isolation of molecules unless the heterodimers between selected aptamers can be strictly excluded.

\section{Conflict of Interests}

The authors declare no competing financial interests.

\section{Authors' Contribution}

Lixue Wang and Chuandong Zhu contributed equally to this paper.

\section{Acknowledgments}

This project was supported by the Research Foundation of Jiangsu Provincial Commission of Health and Family Planning, China (Grant no. H201440); Medical Science and Technology Development Foundation, Nanjing Department of Health (Grant no. YKK14152); Jiangsu Provincial Natural Science Fund (no. BK20141018); “333” Project of Jiangsu Province (no. BRA2013292), Six Major Talent Peak Project of Jiangsu Province (class B, no. WS-047); and the Natural Science Foundation of China (nos. 30670619, 81072017).

\section{References}

[1] L. Wang, W. Asghar, U. Demirci, and Y. Wan, "Nanostructured substrates for isolation of circulating tumor cells," Nano Today, vol. 8, no. 4, pp. 374-387, 2013.

[2] H. J. Yoon, M. Kozminsky, and S. Nagrath, "Emerging role of nanomaterials in circulating tumor cell isolation and analysis," ACS Nano, vol. 8, no. 3, pp. 1995-2017, 2014.

[3] X. Liu and S. Wang, "Three-dimensional nano-biointerface as a new platform for guiding cell fate," Chemical Society Reviews, vol. 43, no. 8, pp. 2385-2401, 2014.
[4] M. Lin, J.-F. Chen, Y.-T. Lu et al., "Nanostructure embedded microchips for detection, isolation, and characterization of circulating tumor cells," Accounts of Chemical Research, vol. 47, no. 10, pp. 2941-2950, 2014.

[5] H. Ma, J. Liu, M. M. Ali et al., "Nucleic acid aptamers in cancer research, diagnosis and therapy," Chemical Society Reviews, vol. 44, no. 5, pp. 1240-1256, 2015.

[6] M. Yu, S. Stott, M. Toner, S. Maheswaran, and D. A. Haber, "Circulating tumor cells: approaches to isolation and characterization," The Journal of Cell Biology, vol. 192, no. 3, pp. 373-382, 2011.

[7] Y. Wan, M. A. I. Mahmood, N. Li et al., "Nanotextured substrates with immobilized aptamers for cancer cell isolation and cytology," Cancer, vol. 118, no. 4, pp. 1145-1154, 2012.

[8] W. Han, B. A. Allio, D. G. Foster, and M. R. King, "Nanoparticle coatings for enhanced capture of flowing cells in microtubes," ACS Nano, vol. 4, no. 1, pp. 174-180, 2010.

[9] W. Chen, S. Weng, F. Zhang et al., "Nanoroughened surfaces for efficient capture of circulating tumor cells without using capture antibodies," ACS Nano, vol. 7, no. 1, pp. 566-575, 2013.

[10] S. Wang, Y. Wan, and Y. Liu, "Effects of nanopillar array diameter and spacing on cancer cell capture and cell behaviors," Nanoscale, vol. 6, no. 21, pp. 12482-12489, 2014.

[11] M. A. I. Mahmood, Y. Wan, M. Islam et al., "Micro+nanotexturing of substrates to enhance ligand-assisted cancer cell isolation," Nanotechnology, vol. 25, no. 47, Article ID 475102, 2014.

[12] J. C. Fischer, D. Niederacher, S. A. Topp et al., "Diagnostic leukapheresis enables reliable detection of circulating tumor cells of nonmetastatic cancer patients," Proceedings of the National Academy of Sciences of the United States of America, vol. 110, no. 41, pp. 16580-16585, 2013.

[13] A. M. Sieuwerts, J. Kraan, J. Bolt et al., "Anti-epithelial cell adhesion molecule antibodies and the detection of circulating normal-like breast tumor cells," Journal of the National Cancer Institute, vol. 101, no. 1, pp. 61-66, 2009.

[14] S.-M. Tu, "Heterogeneity of cancer," in Origin of Cancers, pp. 129-136, Springer, Berlin, Germany, 2010.

[15] Y. Wan, M. Winter, B. Delalat et al., "Nanostructured polystyrene well plates allow unbiased high-throughput characterization of circulating tumor cells," ACS Applied Materials \& Interfaces, vol. 6, no. 23, pp. 20828-20836, 2014.

[16] S. M. Nimjee, C. P. Rusconi, and B. A. Sullenger, "Aptamers: an emerging class of therapeutics," Annual Review of Medicine, vol. 56, pp. 555-583, 2005.

[17] Y. Wan, J. Tan, W. Asghar, Y.-T. Kim, Y. Liu, and S. M. Iqbal, "Velocity effect on aptamer-based circulating tumor cell isolation in microfluidic devices," The Journal of Physical Chemistry B, vol. 115, no. 47, pp. 13891-13896, 2011.

[18] Y. Wan, D. Tamuly, P. B. Allen et al., "Proliferation and migration of tumor cells in tapered channels," Biomedical Microdevices, vol. 15, no. 4, pp. 635-643, 2013.

[19] G. Zhu, L. Meng, M. Ye et al., "Self-assembled aptamerbased drug carriers for bispecific cytotoxicity to cancer cells," Chemistry, vol. 7, no. 7, pp. 1630-1636, 2012.

[20] O. Boyacioglu, C. H. Stuart, G. Kulik, and W. H. Gmeiner, "Dimeric DNA aptamer complexes for high-capacity-targeted drug delivery using ph-sensitive covalent linkages," Molecular Therapy_Nucleic Acids, vol. 2, article e107, 2013.

[21] Y. Wan, Y.-T. Kim, N. Li et al., "Surface-immobilized aptamers for cancer cell isolation and microscopic cytology," Cancer Research, vol. 70, no. 22, pp. 9371-9380, 2010. 
[22] Y. Song, Z. Zhu, Y. An et al., "Selection of DNA aptamers against epithelial cell adhesion molecule for cancer cell imaging and circulating tumor cell capture," Analytical Chemistry, vol. 85, no. 8, pp. 4141-4149, 2013.

[23] S. L. Stott, C.-H. Hsu, D. I. Tsukrov et al., "Isolation of circulating tumor cells using a microvortex-generating herringbonechip," Proceedings of the National Academy of Sciences of the United States of America, vol. 107, no. 43, pp. 18392-18397, 2010. 

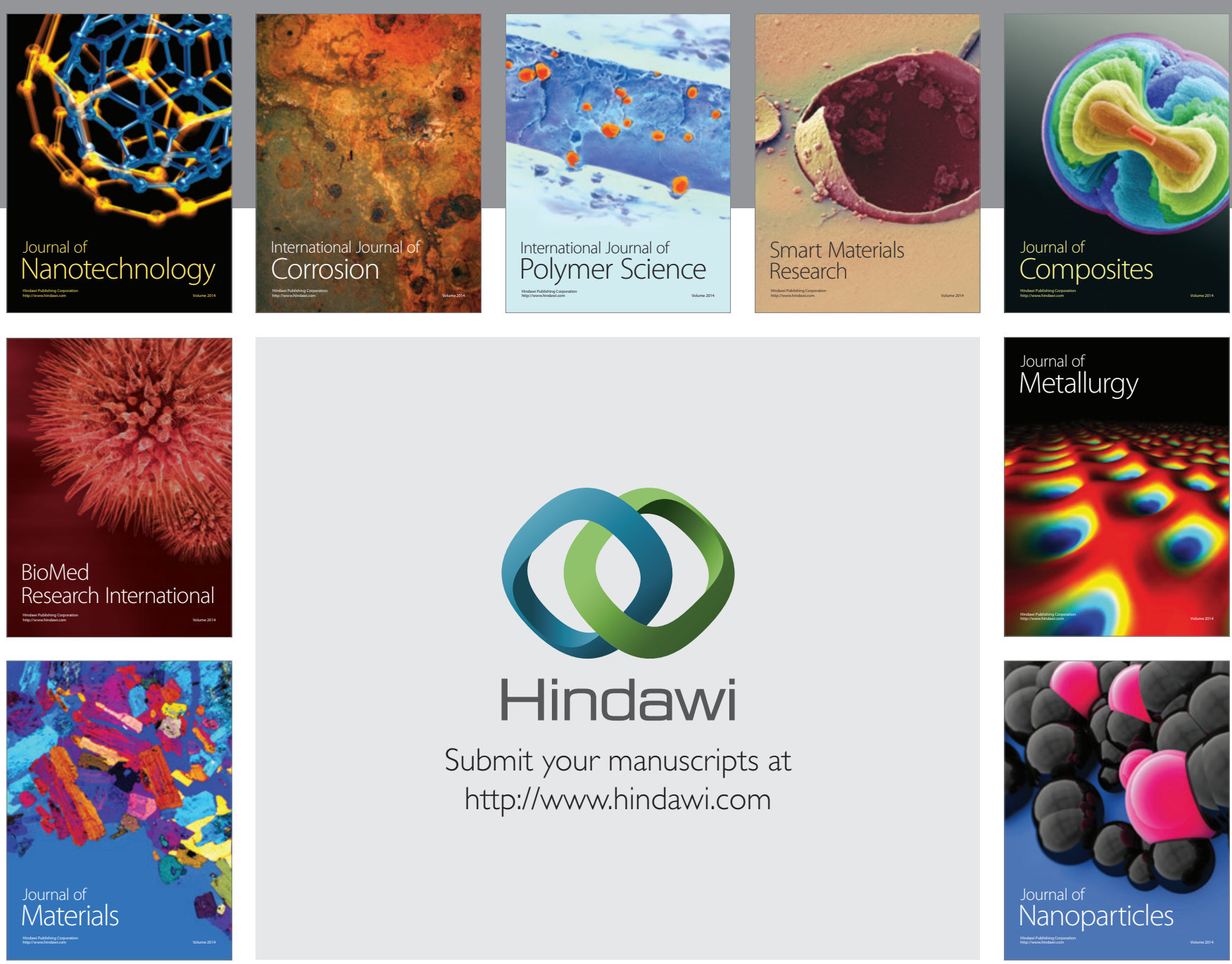

Submit your manuscripts at http://www.hindawi.com
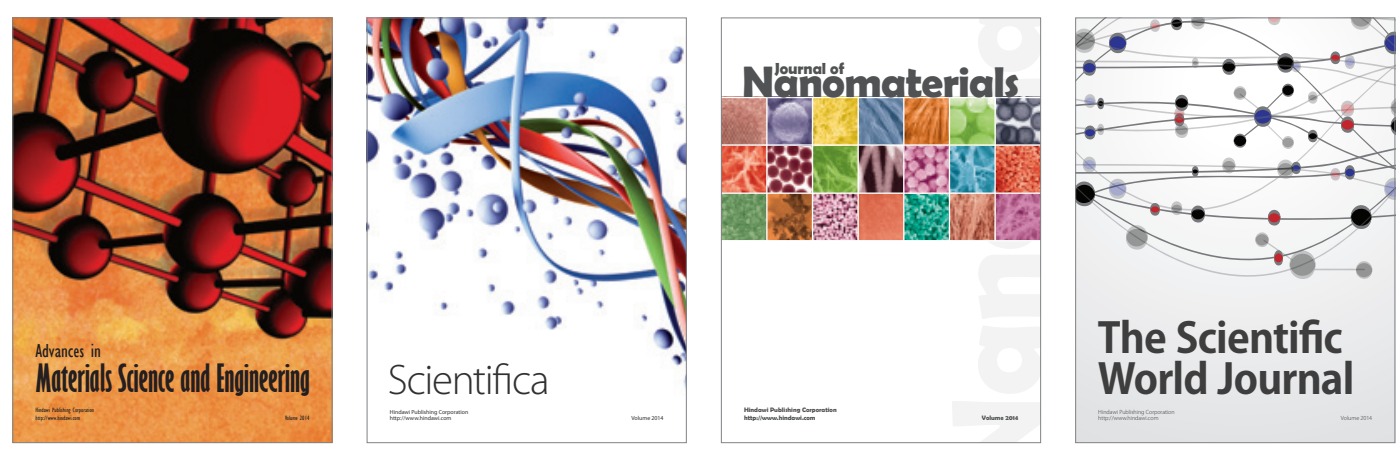

\section{The Scientific World Journal}
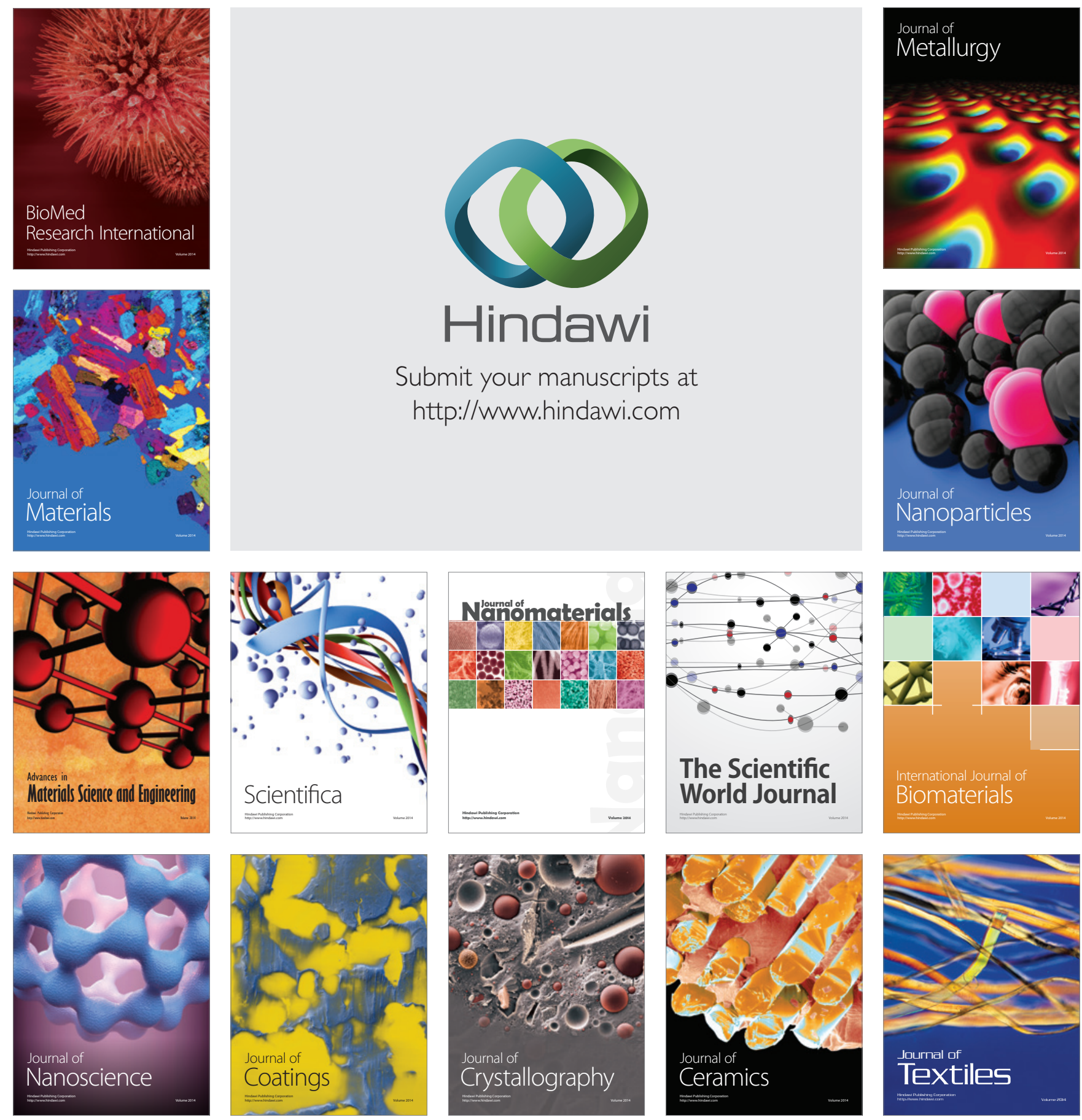